\title{
ATIVIDADE ANTIFÚNGICA IN VIVO DO EXTRATO BRUTO DA LOBELIA LANGEANA \\ DUSÉN, CAMPANULACEAE, FRENTE A UM PATÓGENO DA ERVA-MATE (ILEX PARAGUARIENSIS ST. HIL.)
}

\author{
IN VIVO ANTIFUNGAL ACTIVITY OF LOBELIA LANGEANA DUSÉN \\ (CAMPANULACEAE) AGAINST A PATHOGEN OF MATE \\ (ILEX PARAGUARIENSIS ST. HIL.)
}

CUNICO, M. M. ${ }^{1}$; ANDRADE, C. A. ${ }^{1}$; MIGUEL, O. G. ${ }^{1 *}$; MIGUEL, M. D. ${ }^{1}$; AUER, C. G. ${ }^{2}$; GRIGOLETTI JÚNIOR, A. ${ }^{2}$; CÔCCO, L. C. ${ }^{3}$; YAMAMOTO, C. I. ${ }^{3}$

${ }^{1}$ Laboratório de Fitoquímica, Departamento de Farmácia, Universidade Federal do Paraná.

Av. Prefeito Lothário Meissner, n 632, CEP: 80210170 - Jardim Botânico, CuritibaParaná, Brasil.*E-mail: obdulio@ufpr.br

${ }^{2}$ Embrapa Florestas, Colombo, Paraná, Brasil.

${ }^{3}$ Laboratório de Combustíveis Automotivos (LACAUT), Universidade Federal do Paraná, CP 19081, 81531-990 Curitiba - PR, Brasil.

\section{RESUMO}

Dentre as espécies vegetais da flora nativa brasileira, encontra-se a Lobelia langeana Dusén, erva comum nos estados do Paraná e Santa Catarina, conhecida como "lobélia". Esta planta possui várias propriedades terapêuticas, inclusive a de substituto do tabaco. Um estudo foi desenvolvido para determinar sua fungitoxicidade, para participar de métodos alternativos de controle de fitopatógenos. Neste ensaio preliminar, avaliou-se o efeito de um extrato bruto da lobélia sobre a formação de lesões foliares causadas por Cylindrocladium spathulatum, em folhas destacadas de erva-mate. O extrato da lobélia inibiu em 48,9 \% o desenvolvimento das lesões foliares. Este resultado mostrou que o extrato desta planta pode ser testado para o controle da pinta-preta da erva-mate, em condições de campo.

Palavras-chave: Cylindrocladium spathulatum; erva-mate; lobélia.

\section{ABSTRACT}

Among several plants from Brazilian native flora, there is Lobelia langeana Dusén, common herb in the states of Paraná and Santa Catarina, named as "lobélia". This plant has several therapeutically properties, including a substitute of tobacco. A study was performed to determine its fungitoxicity, participating in alternative control methods of plant pathogens. In this preliminar assay, the effect of a lobelia extract was evaluated on the formation of leaf spots caused by Cylindrocladium spathulatum, in detached leaves of mate. The lobélia extract inhibited the development of foliar lesions in $48,9 \%$. This result showed lobelia extract could be tested for control of mate leaf spot, in field conditions.

Key words: Cylindrocladium spathulatum; lobélia, mate.

\footnotetext{
${ }^{1}$ Departamento de Farmácia, Laboratório de Fitoquímica, Universidade Federal do Paraná.

2 Embrapa Florestas, Colombo, Paraná, Brasil.

${ }^{3}$ LACAUT, Universidade Federal do Paraná, CP 19081, 81531-990 Curitiba - PR, Brasil.
} 


\section{INTRODUÇÃO}

Atualmente, a necessidade de se praticar uma agricultura sustentável devido à importância dada aos produtos vegetais nos mercados nacional e internacional e a crescente resistência de microrganismos fitopatogênicos frente aos fungicidas sintéticos usuais, tem promovido e intensificado estudos que visam a descoberta de métodos alternativos de controle de doenças de plantas (COUTINHO, 1996; KIMATI et al., 1997). Nesta perspectiva, as plantas medicinais, fontes de importantes substâncias fungitóxicas, porém pouco exploradas, caracterizam uma proposta viável e ecologicamente inofensiva ao meio ambiente (STANGARLIN et. al., 1999; CUNICO et al., 2003).

Dentre as inúmeras espécies da flora nativa brasileira com propriedades biológicas de interesse, encontra-se a Lobelia langeana Dusén (Campanulaceae), espécie conhecida popularmente como "lobélia". Propriedades eméticas, adstringentes e antiasmáticas são indicações populares atribuídas à espécies deste gênero, sendo também indicadas como substituto do tabaco (FROM TRINTA \& SANTOS, 1989).

Face às considerações expostas, justifica-se a avaliação in vivo da atividade antifúngica do extrato bruto da L. langeana frente ao isolado Cylindrocladium spathulatum, fungo causador da pinta-preta, principal doença fúngica em folhas adultas da erva-mate, agente causal de até $30 \%$ de perdas de mudas em viveiro e campo (GRIGOLETTI JÚNIOR \& AUER, 1997; KIMATI et al., 1997).

\section{MATERIAL E MÉTODOS}

Material vegetal: Raízes e partes aéreas da L. langeana foram coletadas em fevereiro de 2002, no Município de São José dos Pinhais, no Estado do Paraná. A identificação da espécie botânica foi realizada pelo Dr. Gerdt Hatschbach do Museu Botânico Municipal (MBM) da Prefeitura de Curitiba, Paraná, e um exemplar desta espécie (exsicata) encontra-se depositado no Herbário deste Museu, devidamente catalogado e registrado sob $n^{0} 267.109$.

Preparação do extrato vegetal: Raízes e partes aéreas foram estabilizadas, maceradas à frio por 7 dias em etanol a 95\% em água (1,5 kg/4L). O extrato bruto etanólico seco (EBS) foi obtido após filtração e completa secura em evaporador rotatório $\left(40^{\circ} \mathrm{C}\right)$.

Ensaio Biológico: A atividade antifúngica foi avaliada in vivo, pelo método de QUIRINO et al. (1999), onde testou-se o extrato bruto seco solubilizado em água estéril (EBS) frente ao isolado fitopatogênico $C$. spathulatum fornecido pela Embrapa Florestas (Colombo, PR). Para cada tratamento e controle (EBS, benomyl e água estéril) foram coletadas 10 folhas maduras de erva-mate, as quais foram lavadas com água estéril e tratadas respectivamente com a solução de EBS da L. langeana (1000 ppm) ou com solução de fungicida benomyl (1000 ppm). Para controle, 10 folhas sem tratamento foram reservadas. Em seguida, as folhas foram identificadas e acondicionadas em bandejas forradas com papel de filtro estéril e úmido, com a parte abaxial voltada para cima. Após 24 horas, discos de papel de filtro esterelizados $(6 \mathrm{~mm})$ e impregnados com suspensão de esporos de $C$. spathulatum $\left(1,75 \times 10^{5}\right.$ conídios $\left./ \mathrm{mL}\right)$ foram colocados sobre as folhas previamente preparadas e tratadas ( 2 discos por folha), e mantidas por 7 dias em laboratório à temperatura ambiente e iluminação natural. Após este período de incubação, fez-se a leitura medindo-se a área dos halos de crescimento da colônia a partir de duas medidas diametrais. O delineamento experimental da atividade antifúngica (crescimento micelial) foi inteiramente casualizado e a análise estatística dos resultados obtidos foi realizada empregando-se o Teste de Tukey, com limite de confiança de 95\%, por meio do programa SANEST (ZONTA et al., 1984). 


\section{RESULTADOS E DISCUSSÃO}

Os resultados deste ensaio demonstraram potencial antifúngico da $L$. langeana, pois o seu extrato inibiu cerca de $49 \%$ o crescimento de C.spathulatum em folhas de erva-mate (Tabela 1).

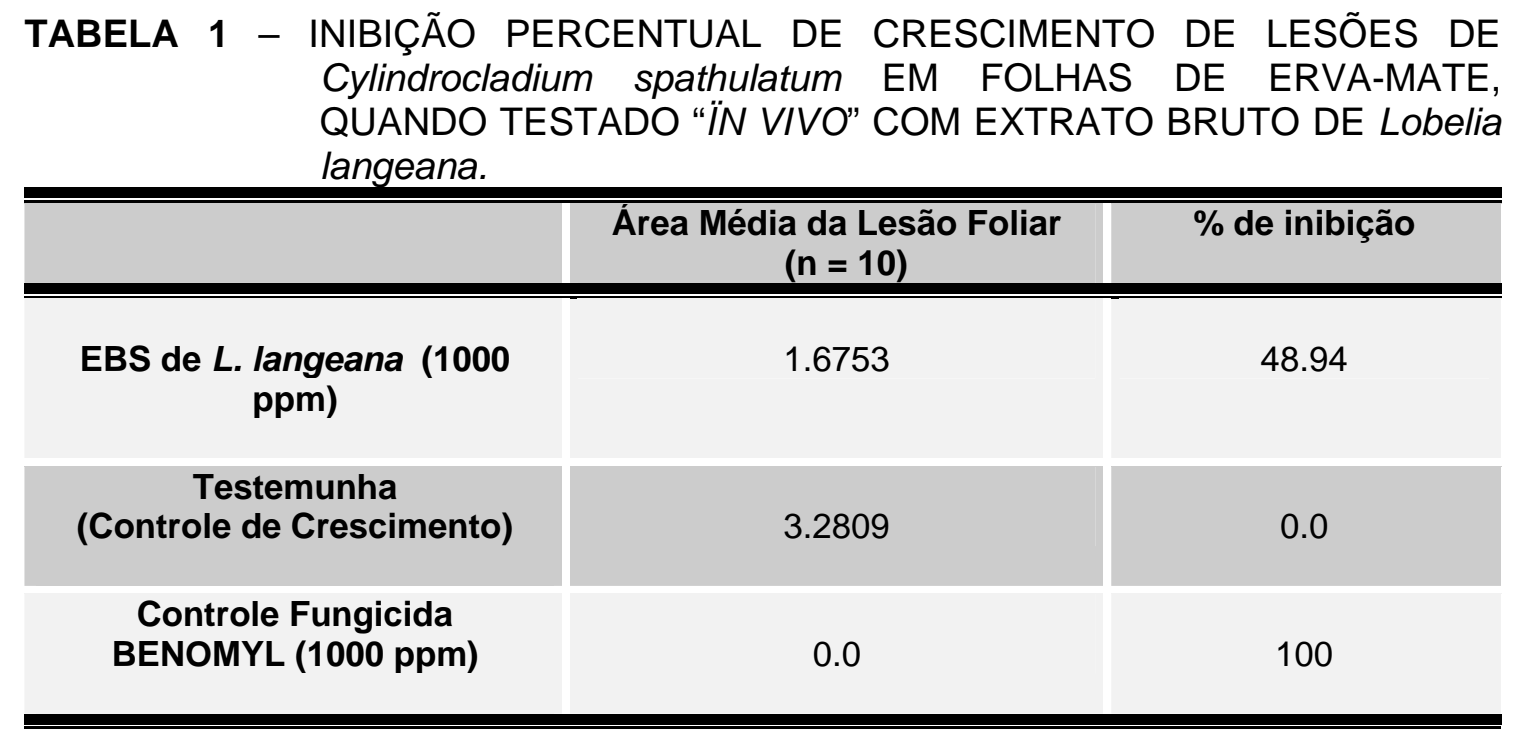

Estudos similares foram realizados com extrato de Ottonia martiana (CUNICO., 2001; CUNICO et al., 2003), cujos resultados exibiram potencial fungitóxico frente ao patógeno $C$. spathulatum em folhas de erva-mate equivalentes aos obtidos pela $L$. langeana.

Sendo assim, esta pesquisa reafirma a necessidade de se realizar novos bioensaios, a fim de identificar as substâncias bioativas, além de reforçar a utilização de plantas medicinais como método alternativo vantajoso, por contemplar a prática de uma agricultura sustentável, sem prejuízos ao meio ambiente.

\section{AGRADECIMENTOS}

Ao Dr. Gerdt Hatschbach do Museu Botânico Municipal da Prefeitura de Curitiba (MBM), pela identificação da espécie vegetal e ao coletor Osmar S. Ribas do MBM ( $\left.{ }^{\circ} 3633\right)$, pela obtenção do material vegetal estudado.

\section{REFERÊNCIAS}

COUTINHO, H. L. C. Diversidade microbiana e agricultura sustentável [online]. CNPS/EMBRAPA, $1996 . \quad$ Disponível em:http://www.bdt.org.br/ marinez/padct.bio/cap9/1/ heitor.html. Acessado em 10 de dezembro de 1999.

Cunico, M. M. Estudo fitoquímico e das atividades antimicrobianas da Ottonia martiana Miq. - Piperaceae. Curitiba: 2001, 81p. [Dissertação (Mestrado) - Ciências Farmacêuticas, Setor de Ciências da Saúde, Universidade Federal do Paraná].

Cunico, M. M.; Miguel, O. G.; Miguel, M. D.; Carvalho, J. L. S.; Peitz, C.; Auer, C. G.; GRIGOLETTI JúNIOR, A. Estudo da atividade antifúngica de Ottonia martiana Miq., Piperaceae: Um Teste in vivo. Visão Acadêmica, v.4, n.2, p.77-82, Jul.-Dez., 2003.

Kimati, H.; Amorim, L. Bergamin Filho, A . Camargo L.E.A , ReZende, J.A.M. Manual de fitopatologia: doenças de plantas cultivadas. v.2. São Paulo: Editora Agronômica Ceres Ltda, 1997. 
Grigoletti Junior, A.; AUer, C.G. DoençAS dA erVA-MATE. KIMATI, H.; AmORIM, L.A.; Bergamin filho, A.; CAMARgo, L.E.A., Rezende, J.A.M. eds. Manual de Fitopatologia. doenças das plantas cultivadas. 3 ed. São Paulo, 1997, v.2, p.345-347.

Quirino, V. F.; SzeremetA, B.; Grigoletti JR, A.; Auer, C. G. Efeito do extrato aquoso de folhas de seis espécies florestais sobre a germinação e crescimento micelial de Cylindrocladium spathulatum e Colletotrichum sp. Summa Phytopathologica, v. 1, n. 1, p. 1-3, 1999.

Stangarlin, J. R., Schwan-Estrada, K. R. F., Silva Cruz, M. E.; Nozaki, M. H. Plantas medicinais e controle alternativo de fitopatógenos. Biotecnol. Ciênc. Desenv., n.11, p.16-21, 1999.

From TRINTA, E.; SANTOS, E. Campanuláceas. Flora Ilustrada Catarinense. Itajaí, Herbário Barbosa Rodrigues, 1989.

ZONTA, E. P.; MACHADO, A. A.; SILVEIRA JÚNIOR, P. Sistema de análise estatística para microcomputadores (SANEST) [Disquete, $3 \frac{1}{1} 2$ pol.]. Pelotas: UFPEL, 1984. Programa estatístico para microcomputadores. 